\title{
Origins of the Solid Bitumens in the Guizhong Depression, China: Evidence From Carbon Isotopes, Sulfur Isotopes and Biomarkers
}

\author{
Xunyun HE*, ANJiAng Shen, ShaOyun XiOng, \\ YUANYUAN HU AND LILI HUANG \\ ${ }^{1}$ PetroChina Hangzhou Research Institute of Geology, \\ Hangzhou 310023, China (*correspondence: \\ hexunyun@sina.com) \\ ${ }^{2}$ Key Laboratory of carbonate reservoirs, CNPC, Hangzhou \\ 310023, China
}

The Guizhong Depression is located in Guangxi Province, SW China, with an area of $4.6 \times 10^{4} \mathrm{~km}^{2}$. After several intensive tectonic movements, currently the Devonian and Carboniferous marine strata were mainly remained [1]. The solid bitumens were extensively occurred in the Devonian marine carbonate. A bitumen-source rock correlation method based on carbon isotopes, sulfur isotopes and biomarkers is described for potential source rocks and bitumens in the Guizhong Depression to elucidate the origins of the solid bitumens. The results show that the Lower Devonian bitumens have the $\delta^{13} \mathrm{C}$ values of $-26.8 \%$ to $-23.0 \%$, with the average of $-25.4 \%$; the Middle Devonian bitumens have the $\delta^{13} \mathrm{C}$ values of $-24.1 \%$ to $-23.3 \%$, average $-23.8 \%$; the Upper Devonian bitumens have the $\delta^{13} \mathrm{C}$ values of $-28.0 \%$ to $24.6 \%$, average $-26.3 \%$. The $\delta^{34} \mathrm{~S}$ values of the Lower and Middle Devonian bitumens range from $-2.69 \%$ to $+2.11 \%$, $+9.41 \%$ to $+11.08 \%$, respectively. The potential source rocks of the Lower Cambrian in the adjacent Qiannan Depression have the $\delta^{13} \mathrm{C}$ values of $-35.79 \%$ to $-29.88 \%$, average $32.85 \%$ [2], and the potential source rocks of the Lower and Middle Devonian in the Guizhong Depression have the $\delta^{13} \mathrm{C}$ values of $-27.80 \%$ to $-26.50 \%,-27.60 \%$ to $-24.60 \%$, respectively. The $\delta^{34} \mathrm{~S}$ values of the Lower Cambrian source rocks in the adjacent Qiannan Depression range from $+14.78 \%$ o to $+17.60 \%$ [ [2]; The $\delta^{34} \mathrm{~S}$ values of the Lower and Middle Devonian source rocks in the depression range from $9.10 \%$ to $+6.78 \%$, $+0.63 \%$ o to $+7.93 \%$, respectively. Moreover, the biomarkers abstracted from the bitumens are similar to those of the Lower and Middle Devonian source rocks, while not similar to those of the Lower Cambrian source rocks. Thus it could be concluded that the Devonian solid bitumens of the Guizhong Depression were sourced from the Lower and Middle Devonian source rocks in the depression.

[1] Zeng et al(1995). ACTA GEOL SIN,69:113-124. [2] HE et al (2014). ACTA PETROL SIN, 29:1059-1072. 